distribuindo-se por quatro trimestres, o último dos quais terminará em Dezembro de 1995.

Sob a competente direcção do Prof. Doutor Fernando do Nascimento (da FCEE/UCP), o Curso de Pós-graduação é frequentado por 29 alunos, que estão inscritos nos 12 módulos que integram o respectivo plano curricular, e por três licenciados com o estatuto de alunos externos.

\title{
3. HOMENAGEM A MONSENHOR CELSO TAVARES DA SILVA
}

Na sequência de iniciativa da Reitoria da Universidade Católica Portuguesa e da Diocesse de Viseu, foi prestada homenagem, no dia 05 de Novembro de 1994, a Monsenhor Celso Tavares da Silva, que foi dedicado e competente Secretário do Centro Regional de Viseu da UCP e Membro do Conselho de Direç̧ão do I.U.D.P.S., de 1989 a 1994.

A referida homenagem, a que se associou intensamente o I.U.D.P.S., comportou diveros actos, de que se destacam a Missa celebrada por S. Ex. ${ }^{a}$ Rev $^{\text {ma }}$ o Senhor Bispo de Viseu, no Seminário Maior de Viseu, e a sessão solene, realizada no Auditório Engenheiro Engrácia Carrilho, à qual presidiu o Magnífico Reitor da Universidade Católica Portuguesa.

Como tributo de homenagem a Monsenhor Celso, o Conselho de Direç̧ão e os docentes do I.U.D.P.S. ofereceram-lhe uma salva de prata, tendo também estado presentes, na sessão solene, numerosos professores e estudantes do Instituto. No decurso daquela, usaram da palavra: os Directores do I.U.D.P.S. e da Faculdade de Letras, o Presidente do Centro Regional das Beiras, S. Ex. ${ }^{\mathrm{a}}$ Rev. ${ }^{\mathrm{ma}}$ o Senhor Bispo de Viseu, o Magnífico Reitor da Universidade Católica Portuguesa e o homenageado.

Como coroamento da referida homenagem, o I.U.D.P.S. dedicará o $4 .^{\circ}$ volume de GESTÃO E DESENVOLVIMENTO a uma miscelânea de estudos em honra de Monsenhor Celso Tavares da Silva.

\section{CERIMÓNIA DE BENÇÃO E ENTREGA DE DIPLOMAS DA LICENCIA- TURA EM GESTÃO E DESENVOLVIMENTO SOCIAL}

Dando continuidade a uma tradição, iniciada em Janeiro de 1993, no que concerne à licenciatura em Gestão e Desenvolvimento Social, realizou-se, no dia 14 de Janeiro do corrente ano, a cerimónia de bênção e entrega de diplomas aos 
novos licenciados em Gestão e Desenvolvimento Social, bem como em Humanidades e Português-Francês.

A cerimónia foi presidida, como habitualmente, pelo Magnífico Reitor da Universidade Católica Portuguesa, tendo a presença de S. Ex. ${ }^{a}$ Rev. ${ }^{\text {ma }}$ o Senhor Bispo de Viseu e das principais autoridades do Distrito, além de professores e alunos da Universidade Católica, dos novos licenciados e de suas famílias.

Na cerimónia, usaram da palavra o Presidente do Centro Regional das Beiras, S. Ex..$^{a}$ Rev ${ }^{\text {ma }}$ o Senhor Bispo de Viseu e o Magnífico Reitor da Universidade Católica.

Proferiu a oração de sapiência o Prof. Doutor José Maria Amado Mendes, Professor Catedrático da Faculdade de Letras da Universiadade de Coimbra e do Instituto Universitário de Desenvolvimento e Promoção Social que, com grande brilhantismo, versou o tema "Sucesso e inovação no mundo empresarial: Perspectiva histórica", estudo que publicaremos no próximo volume desta revista.

Receberam o seu diploma cinquenta e dois novos licenciados em Gestão e Desenvolvimento Social.

\section{PROVAS ACADÉMICAS}

\section{DOUTORAMENTO EM CIÊNCIAS SOCIAIS DA DR. ${ }^{\text {a }}$ MARIA OLÍVIA DIAS}

No passado mês de Junho, concluiu, na Pontifícia Universidade Gregoriana de Roma, as suas provas de doutoramento em Ciências Sociais a Dr. ${ }^{a}$ Maria Olívia Dias, docente do Instituto Universitário de Desenvolvimento e Promoção Social desde o ano lectivo de 1986/87.

A nova doutora apresentou uma dissertação, intitulada $A$ instrução e o trabalho da mulher. Mudança qualitativa do trabalho feminino no distrito de Viseu, a qual foi, numa fase inicial, orientada pelo Prof. Doutor Pedro C. Beltrão, S. J., e, posteriormente ao falecimento deste professor, pela Prof. ${ }^{a}$ Doutora Eleonora Massini, da Faculdade de Ciências Sociais da P.U.G. de Roma.

O Júri atribuiu à nova doutora a classificação «cum laude».

Gestão e Desenvolvimento felicita a Doutora Maria Olívia Dias pela conclusão do seu doutoramento e augura-lhe as maiores felicidades no prosseguimento da sua carreira. 